\title{
Fast and Reliable Locating of Points with the Maximum Value of Total Electromagnetic Field Using a Modern Experimental Method for Radio Coverage in Urban Environment
}

\author{
Petar S. Medjedovic ${ }^{1}$ and Darko S. Suka ${ }^{2}$ \\ ${ }^{1}$ Faculty of Electrical Engineering, University of Banja Luka, 78000 Banja Luka, Bosnia and Herzegovina \\ ${ }^{2}$ Faculty of Electrical Engineering, University of East Sarajevo, 71123 East Sarajevo, Bosnia and Herzegovina
}

Correspondence should be addressed to Darko S. Suka; darko.suka@etf.unssa.rs.ba

Received 5 January 2014; Accepted 14 April 2014; Published 20 May 2014

Academic Editor: Panayiotis Frangos

Copyright (C) 2014 P. S. Medjedovic and D. S. Suka. This is an open access article distributed under the Creative Commons Attribution License, which permits unrestricted use, distribution, and reproduction in any medium, provided the original work is properly cited.

\begin{abstract}
This research has been performed within the project "prediction, measurement, and analysis of composite electromagnetic field of artificial radiation sources," funded by the Ministry of Science and Technology of the Republic of Srpska, Bosnia and Herzegovina. The ultimate goal of the project is the installation of a monitoring network for continuous measurement and recording of nonionizing electromagnetic (EM) radiation levels in the wider area of Banja Luka city centre covering about $10 \mathrm{~km}^{2}$. For this reason it was necessary to make an optimal choice from a dozen of measurement points with the maximum value levels of total EM field. It was a difficult task, because in this case, with the resolution of $5 \mathrm{~m} \times 5 \mathrm{~m}$, approximately 400,000 points should be examined. Therefore, the pedestrian zones, areas, and routes with significantly smaller surfaces but with the largest flow of people have been examined, so the time required for their mapping with values of total EM field has been reduced to a more realistic framework. In this paper, in the volume allowed by the defined criteria, a fast and reliable experimental method has been described, which has been examined at one of the studied areas in the named project, with surface of $0.008 \mathrm{~km}^{2}$.
\end{abstract}

\section{Introduction}

Public systems of mobile telephony are nowadays commonplace communication technology around the world. This wireless technology relies upon an extensive network of fixed antennas or base stations, exchanging information by means of radio frequency (RF) signals. About two million base stations exist worldwide and the number is increasing significantly with the introduction of fourth generation technology devices and also with planning and developing the fifth generation of it. During the last decade, the installation and operation of several wireless networks, such as GSM, UMTS, TETRA, and Wi-Fi systems, have led to an increasing public concern about the exposure to EM radiation emitted by such sources. In conjunction with traditional broadcasting systems (FM Radio and VHF-UHF TV), radar systems, and so forth, these concerns require the continuous information regarding public exposure to EM radiation levels. The first step for estimating the exposure levels is the so-called "ad hoc" measurements. Those measurements are referred to a specific time (usually 1-2 hour during the day, e.g. during the peak traffic hour) and date. On the other hand, the notion of continuous measurement of EM radiation levels on a basis of 24 hours is more appealing to the concerned public. Namely, due to the fact that the radio-frequency range is active 24 hours a day, the monitoring process must cover the same period of time, as well. Only under such conditions, the full image on the use of the observed frequency ranges can be acquired. This is due to the fact that the recorded values can be directly compared to the public exposure limits (reference levels-safety values), which are set by the relevant organizations, such as ICNIRP [1], and local governmental authorities [2]. Namely, the protection against acute health effects is defined through exposure limits that are given as the 
values of electric, magnetic, and electromagnetic field which shall never be exceeded in any exposure condition [2]. Also, the quality targets are the set of field safety values that should be pursued, when a new telecommunication infrastructure is planned, as discussed in [3]. It is not important if the structure is isolated or inserted in a context where other installations already exist. As an example, during a base station planning phase, it is necessary to take into account the fact that the field level in proximity of the structure should not exceed the quality targets, no matter if the station is a single structure or coexisting with other similar installations. In such case, a reduction of emitted power by the station itself or by the surrounding emitting structures should be imposed. Furthermore, the same quality targets may be imposed by the local authorities in densely crowded areas (like airports and railway stations, etc.) even in the case of a reduced presence time.

For that reason, a network for the measurement and recording of nonionizing electromagnetic radiation levels during 24 hours is one of the best solutions serving such purposes, as discussed in $[3,4]$. Another important parameter of such network is the ability to present the measurement results to the public via a user-friendly web site. This is also necessary for practical reasons, because in real life the authorized use of frequency spectrum does not guarantee that it is properly used. This can happen due to complex or incorrect equipment, interaction with other types of equipment, or intentional abuse.

It is possible that the main concern in monitoring network design was to ensure the independence of the measurements carried out, so the citizens might be confident that the presented results were not influenced by particular interests, such as those from telecommunication operators, as well as political parties or other similar groups. To this aim, network must be entirely funded by public money, without any form of sponsorship by operators or other noninstitutional subjects.

In addition, in monitoring networks design, it is important that measuring points, in which sensors sensitive to EM fields would be placed, are chosen as the best representatives in the project area. Representative measuring points for the monitoring network are those with the maximum EM field levels of nonionizing radiation.

As the treated area was approximately $10 \mathrm{~km}^{2}$, with a resolution of $5 \mathrm{~m} \times 5 \mathrm{~m}$, the number of potential measurement points was about 400,000. Measurement of EM field radiation in all these points would require a few years. Because of that, a way had to be found to locate the points with the maximum levels in reasonable and acceptable time. For now, it was possible to proceed only with the assistance of fast and reliable experimental method (discussed here), based on occupancy quality software for urban EM wave propagation modelling [5].

\section{Fast and Reliable Experimental Method}

Under this method, the following activities are considered:

(a) software prediction of the total EM field on the surface with a good resolution which means acceptable and reasonable number of points (e.g., 320), (b) measurement of total EM field at the same points,

(c) measurement and prediction results comparison,

(d) software prediction of total EM field on observed area of $10 \mathrm{~km}^{2}$ in a great number of points (e.g., 400,000),

(e) locating of points with maximum value of total EM fields,

(f) additional measurement at point(s) with maximum electric field value(s) and immediate surrounding area of that point(s).

So, first the software prediction of total power density and total electric field strength for each of all the existing licensed sources of electromagnetic radiation was separately conducted, except microwave links and professional mobile radio (PMR), such as GSM900 MHz, DCS1800 MHz, UMTS $2100 \mathrm{MHz}$, FM radio, TV 5-12th channels, and TV 21-66th channels. All necessary relevant technical data about these sources were obtained from the Communications Regulatory Agency of Bosnia and Herzegovina. The simulation was performed by using a powerful software tool, Wireless InSite (WI) [6], developed by Remcom USA company. In this case, an area of approximately $0.008 \mathrm{~km}^{2}$ was observed, with a resolution of $5 \mathrm{~m} \times 5 \mathrm{~m}$ (320 points). This program predicts how the locations of the transmitters and receivers within an urban area affect signal strength, also models the physical characteristics of rough terrain and urban building features, performs the electromagnetic calculations, and then evaluates the signal propagation characteristics. The computations are ray based with reflections from ground (triangular pixels) as well as from building walls and roofs. Wireless InSite makes these calculations by shooting rays from the transmitters and propagating them through the defined environment. These rays interact with environmental features and make their way to the receivers. Interactions include reflection of the ground or of the building surface, diffraction of the building edge, or transmission through the wall. The selected propagation model is Full 3D, which is the most complex from the viewpoint of computation time. This model places no restriction on object shape and includes transmission through surfaces. The selected ray tracing method is SBR (Shot-and-Bounce Ray). Ray paths are traced without regard to the location of specific field points. Rays are first traced from the source points. Some of them that hit building walls would be reflected and then continue to be traced up to the maximum number of reflections. For the particular application, rays are stopped when they hit the study area boundary. WI combines the ray paths, which follow nearly the same path through environment, with the phase. It then adds the powers of all the correlated groups. Software prediction results are given in the form of colour maps, tables, and diagrams. The measurements were performed by using $\mathrm{FSH} 3$ spectrum analyzer from Rohde\&Schwarz $[7,8]$. The measurement results are also presented in the form of tables and diagrams.

2.1. EM Field Prediction at Krajina Square. Krajina square shown in Figure 1, together with seven typical routes, was 


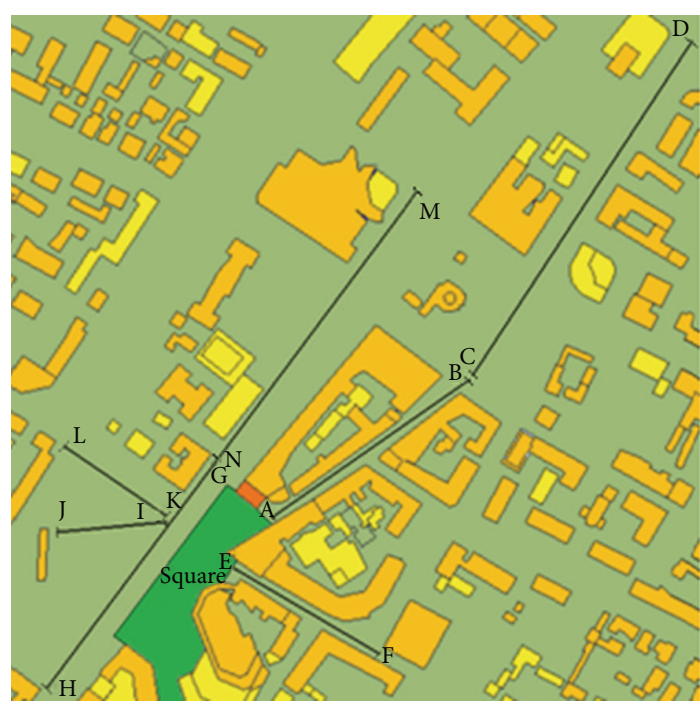

FIgURE 1: Observed surface and routes in the city centre.

chosen for this occasion, as the busiest pedestrian zone with the largest population flow in the city.

For quality and reliable software prediction of the electromagnetic field spatial distribution, or to simulate the propagation of EM waves, it is necessary to possess highquality prediction and simulation software; databases to store the location and technical details of all transmitters and antennas; digital maps that contain terrain heights at locations with a resolution good enough and a map that shows land use (e.g., urban, rural, etc.) as the terrain height map of the observed area; appropriate computer hardware capacity. Wireless InSite software provides efficient and accurate predictions of radio wave propagation and communication channel characteristics in complex urban, suburban, indoor, rural, and mixed path environments.

Before the software prediction of the spatial distribution of EM fields for the observed area of $10 \mathrm{~km}^{2}$ was carried out, all relevant data about sources of EM radiation were collected in the database. That enabled the data entry to WI program for

(i) 29 GSM900 MHz base stations- (BS-) 85 sectors (transmitters),

(ii) 19 DCS1800 MHz BS-49 transmitters,

(iii) 41 UMTS2100 MHz BS-121 transmitters,

(iv) $25 \mathrm{TV}$ transmitters,

(v) $31 \mathrm{FM}$ radio transmitters.

By using WI editing tools, virtual objects and surrounding terrain can be constructed or the same data can be imported from several different formats such as DXF, Shapefile, DTED, and USGS. In this case, a digital map of Banja Luka city in GK6 map projections, made by GisData Effective Solutions company from Zagreb, Croatia, was used [9].

GIS data represent real objects and parameters such as buildings, roads, trees, water flows, height, length, and configuration of terrain in digital form. Digital orthophotos of observed area are the satellite images with resolution of 1 meter in Tiff format. 3D models of all buildings have height attributes (the absolute height of the building and the relative height of the building).

Data for objects and terrain are given in ESRI shape format, whereby the available terrain model has $20 \mathrm{~m} \times 20 \mathrm{~m}$ resolution and a height accuracy of $10 \mathrm{~m}$. Adaptation of digital data used for WI software was successfully performed only after consultation with the manufacturer of the program and additional data conversion.

Thanks to the WI program and all submitted data, it was possible to make the simulation of physical characteristics of rugged terrain and buildings in urban environment, to calculate the electric field strength (EFS) due to the presence of buildings, facilities, and terrain on EM wave propagation, and finally to evaluate the signal propagation characteristics in the frequency range from $50 \mathrm{MHz}$ to $40 \mathrm{GHz}$. More details about this are described in $[10,11]$.

Software prediction of the spatial distribution of total electric field strength $\left(E_{\mathrm{rms}}\right)$, caused by the radiation of all GSM900, DCS1800, UMTS2100, TV5-12th, TV21-66th, and FM radio transmitters, on the surface of approximately $0.008 \mathrm{~km}^{2}$ in the centre of Banja Luka, was shown on six maps in Figure 2. Figure 2 is a magnified part of the square from Figure 1, and white areas on all maps represent buildings and structures. Software prediction of $E_{\mathrm{rms}}$ was performed with the resolution of $5 \mathrm{~m} \times 5 \mathrm{~m}$, which means that the appropriate value of $E_{\mathrm{rms}}$ is assigned to each of the 320 points and is symbolically represented in colour and in accordance with the legend below the maps. The points were numbered in the same manner as the WI program numbers the receiving points from left to right, so the 1st point is placed in the lower left and the 320th point is placed in the upper right corner of the observed surface, as shown in Figures 2 and 3. Each new row begins with a number which is higher for one number than the last number of the previous neighbouring row, (e.g. first row ends with number 4 , the second row starts with number 5) as shown in Figure 4 as well.

WI software counts the total electric field strength like root mean square. For example, $E_{\mathrm{rms}}$ caused by radiation from 85 GSM900 transmitters for $n=1$ to 320 points is calculated according to

$$
E_{\mathrm{rmsn}}=\sqrt{E_{1}^{2}+E_{2}^{2}+E_{3}^{2}+\cdots+E_{85}^{2}} .
$$

It is obvious in Figure 2 that the dominant colours are for GSM900 MHz (a) yellow and orange; DCS1800 MHz (b) and UMTS2100 MHz (c) orange and red; TV5-12th (d), TV2166th (e), and FM radio (f) yellow and green. So, in accordance with the legend, it can be concluded that

(a) DCS1800 MHz transmitters are the biggest and FM radio broadcasters are the smallest "polluters" of the environment, in this case;

(b) the mobile telephony transmitters are larger "polluters" of the environment than television and radio broadcasters, in this case. 


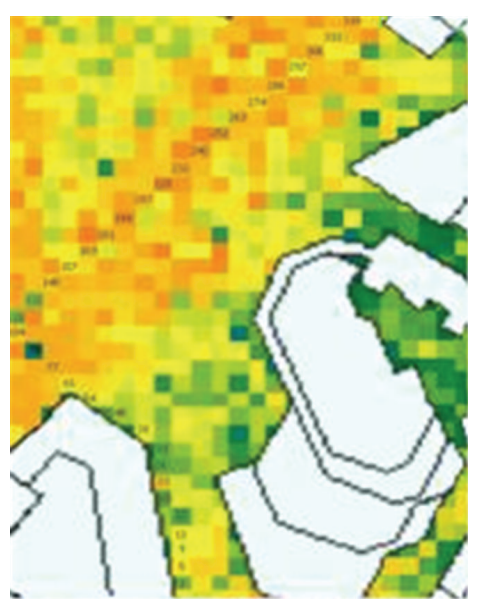

(a)

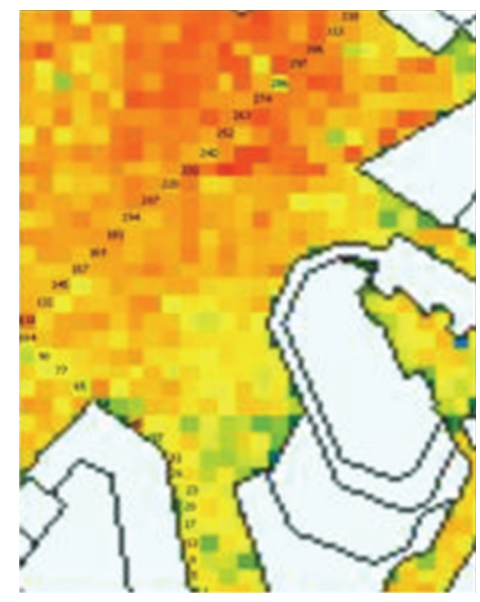

(b)

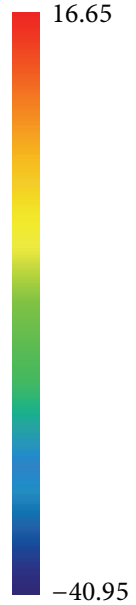

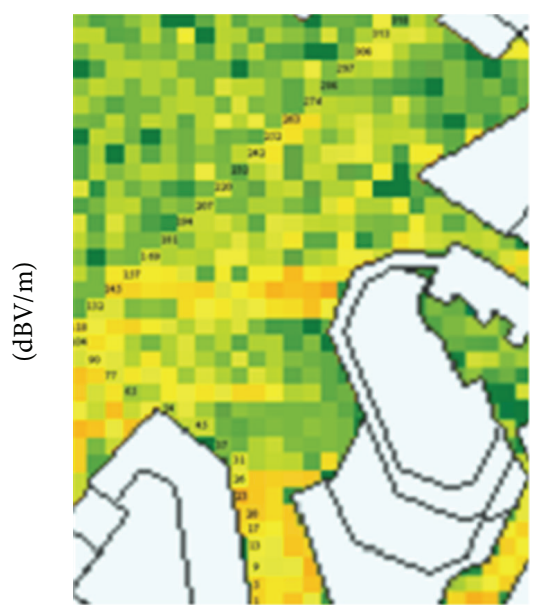

(e)

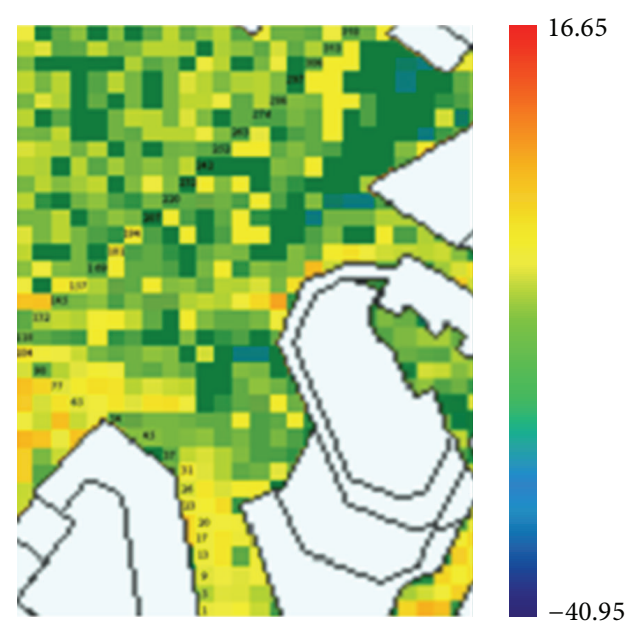

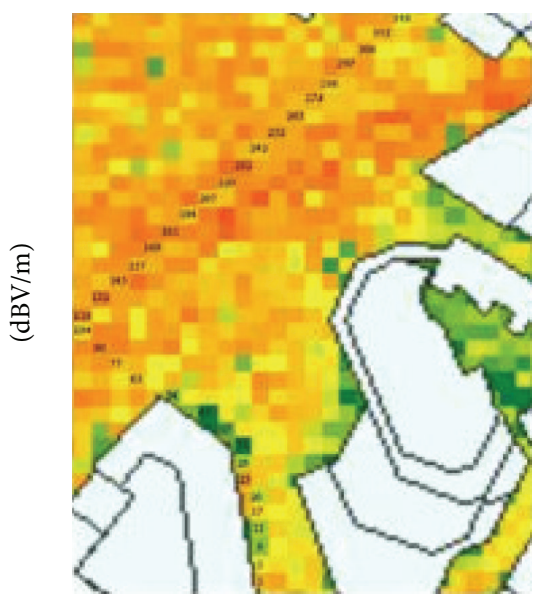

(c) (d)

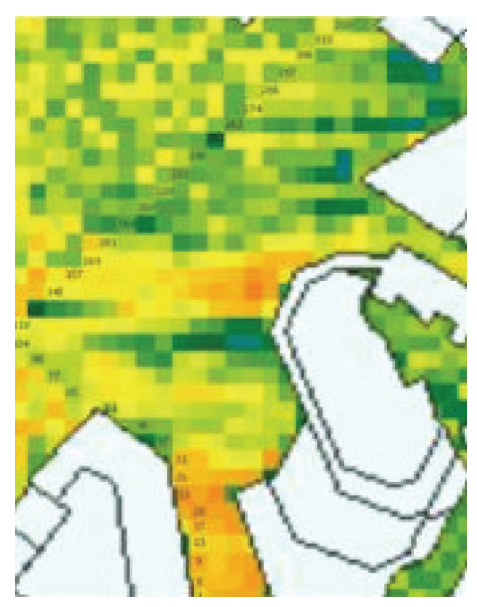

16.65

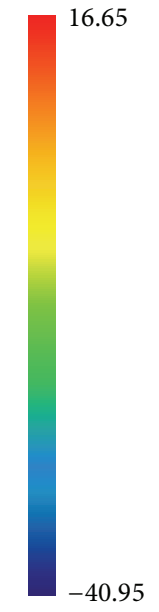

(f)

FIGURE 2: Software prediction of electric field strength for (a) GSM900; (b) DCS1800; (c) UMTS2100; (d) TV5-12; (e) TV21-66; (f) FM radio at Krajina Square in 320 points.

WI software separately displays the results in the form of tables for each studied source of radiation, but due to the very limited space in this paper, it is not possible to show all of it. For the same reason, it is not possible to show the complete schedule for all 320 points. Therefore, Table 1 summarizes 24 maximum $E_{\mathrm{rms}}$ values like the example of software prediction results for DCS1800 MHz at 320 observed points. $X(\mathrm{~m}), Y$ $(\mathrm{m})$, and $Z(\mathrm{~m})$ point coordinates are defined as the receiving 
TABLE 1: Software prediction of total electric field strength for DCS1800 MHz.

\begin{tabular}{lcccccc}
\hline PP & $\mathrm{Rx}$ & $X(\mathrm{~m})$ & $Y(\mathrm{~m})$ & $Z(\mathrm{~m})$ & Distance & $E_{\text {rms }}$ \\
\hline 23 & 5706 & 250 & 195 & 166.1 & 160.43 & 0.43 \\
94 & 6861 & 225 & 235 & 165.2 & 143.71 & 1.00 \\
118 & 7147 & 205 & 245 & 165.2 & 151.97 & 1.80 \\
146 & 7440 & 220 & 255 & 165.5 & 134.90 & 0.46 \\
181 & 7877 & 230 & 270 & 165.5 & 119.19 & 1.54 \\
184 & 7880 & 245 & 270 & 165.5 & 108.09 & 0.80 \\
197 & 8026 & 250 & 275 & 165.8 & 101.76 & 1.46 \\
209 & 8171 & 250 & 280 & 165.8 & 99.09 & 1.52 \\
210 & 8172 & 255 & 280 & 165.8 & 95.54 & 1.09 \\
221 & 8316 & 250 & 285 & 166.1 & 96.60 & 1.54 \\
232 & 8461 & 250 & 290 & 166.1 & 94.32 & 2.49 \\
234 & 8463 & 255 & 285 & 166.1 & 92.95 & 3.97 \\
235 & 8464 & 260 & 285 & 166.1 & 89.44 & 3.26 \\
237 & 8466 & 270 & 285 & 166.1 & 82.86 & 1.86 \\
244 & 8609 & 265 & 295 & 166.4 & 81.15 & 3.04 \\
245 & 8610 & 270 & 295 & 166.4 & 77.74 & 3.16 \\
247 & 8612 & 280 & 295 & 166.4 & 71.49 & 2.28 \\
250 & 8615 & 295 & 295 & 166.1 & 63.92 & 2.05 \\
255 & 8756 & 275 & 300 & 166.4 & 72.22 & 2.33 \\
261 & 8762 & 305 & 300 & 166.4 & 57.59 & 2.00 \\
269 & 8905 & 295 & 305 & 166.4 & 58.85 & 1.72 \\
273 & 8909 & 315 & 305 & 166.4 & 52.89 & 2.42 \\
288 & 9193 & 285 & 315 & 166.4 & 60.61 & 2.76 \\
304 & 9344 & 315 & 320 & 166.4 & 47.31 & 2.41 \\
\hline $\mathrm{PP}$ & & & \\
$\mathrm{P}$ & 250 &
\end{tabular}

PP: Prediction Point.

points $\mathrm{Rx}$, with the assigned numbers $(5706 \cdots 9344)$ by WI software.

Figure 3 shows software prediction of total electric field strength obtained according to (2) for each of the 320 points. Consider the following:

$$
E_{T}=\sqrt{E_{900}^{2}+E_{1800}^{2}+E_{\mathrm{UMTS}}^{2}+E_{\mathrm{TV} 5-12}^{2}+E_{\mathrm{TV} 21-66}^{2}+E_{\mathrm{FM}}^{2}} .
$$

As expected in Figure 3, red colour is the prevailing one, which means that the average total field value is about $6 \mathrm{dBV} / \mathrm{m}(2 \mathrm{~V} / \mathrm{m})$ in accordance with the legend below. Visually, using simple method, as it was explained in [6], points with minimum $(-5 \mathrm{dBV} / \mathrm{m}$ or $0.55 \mathrm{~V} / \mathrm{m}))$ and maximum $(12.5 \mathrm{dBV} / \mathrm{m}$ or $4.2 \mathrm{~V} / \mathrm{m})$ values of EM fields can be located, respectively.

Also, Table 2 shows the software predictions of total electric field strength at 24 points with potential maximum values. In the first column, 24 points $(23 \cdots 304)$ are selected, and in the second, third, fourth, fifth, sixth, and seventh columns are the software predictions of total electric field strength for GSM900, DCS1800, UMTS2100, TV5-12th, TV21-66th, and FM radio, respectively.

Total electric field strength according to (2) and quotients between the above mentioned total values and their public

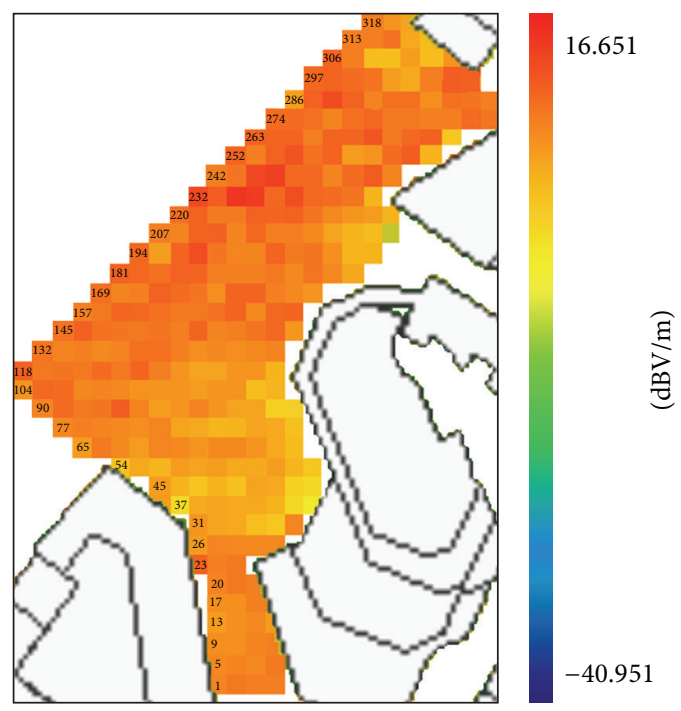

FIGURE 3: Total electric field strength software prediction map.

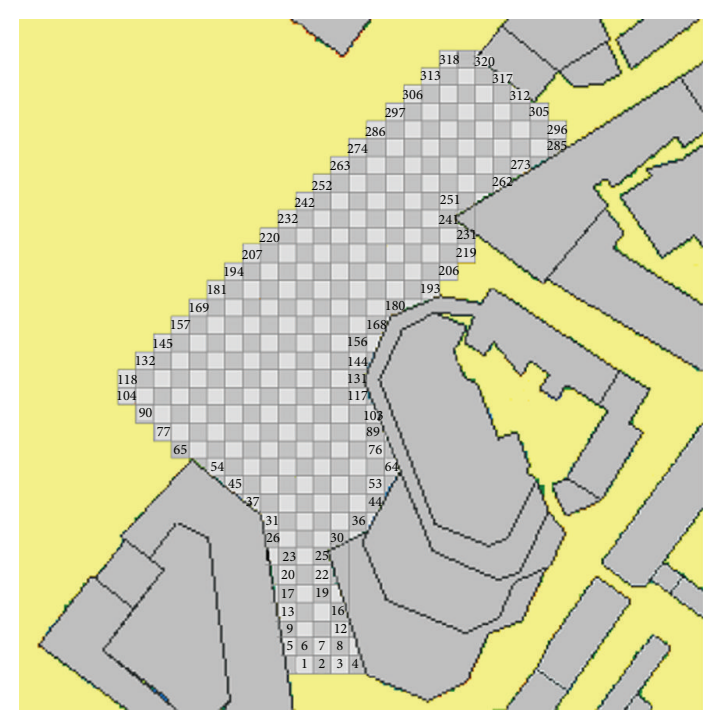

FIGURE 4: Numeration of the prediction points.

exposure limits $\left(E_{T} / E_{L}\right)$ obtained according to (3) are shown in the last two columns. Consider the following:

$$
\sum_{1 \mathrm{MHz}}^{300 \mathrm{GHz}} \frac{E_{T}}{E_{L}} \leq 1
$$

The $E_{L}$ value is the standard threshold for electric field strength value in $\mathrm{V} / \mathrm{m}$, expressed as a function of frequency $f$ defined in [1]. It is obvious that the expected value of the total electric field strength is significantly below all limits prescribed in $[1,2]$. Also, in all prediction points, a condition for the reference values in (3) is fully satisfied, in the case of electromagnetic fields caused by multiple sources at different frequencies [2]. 
TABLE 2: Software prediction of total electric field strength at 24 points with maximum values.

\begin{tabular}{|c|c|c|c|c|c|c|c|c|}
\hline $\mathrm{PP}$ & $\begin{array}{c}E_{\mathrm{rmsl}}(\mathrm{V} / \mathrm{m}) \\
{[\mathrm{GSM} 900]}\end{array}$ & $\begin{array}{c}E_{\mathrm{rms} 2}(\mathrm{~V} / \mathrm{m}) \\
{[\mathrm{DCS} 1800]}\end{array}$ & $\begin{array}{c}E_{\mathrm{rms} 3}(\mathrm{~V} / \mathrm{m}) \\
{[\mathrm{UMTS}]}\end{array}$ & $\begin{array}{c}E_{\mathrm{rms} 4}(\mathrm{~V} / \mathrm{m}) \\
{[\mathrm{TV} 5-11]}\end{array}$ & $\begin{array}{l}E_{\text {rms5 }}(\mathrm{V} / \mathrm{m}) \\
{[\mathrm{TV} 21-66]}\end{array}$ & $\begin{array}{c}E_{\mathrm{rms} 6}(\mathrm{~V} / \mathrm{m}) \\
{[\mathrm{FM} \text { radio] }}\end{array}$ & $\sum\left(E_{T} / E_{L}\right)$ & $E_{T}$ \\
\hline 23 & 0.7555 & 0.4305 & 1.4085 & 1.4387 & 0.9917 & 0.4986 & 0.3766 & 2.4580 \\
\hline 94 & 0.9398 & 0.9975 & 1.6934 & 0.6510 & 0.3210 & 0.5010 & 0.2974 & 2.3503 \\
\hline 118 & 0.2391 & 1.8032 & 1.4255 & 0.4869 & 0.5969 & 0.2461 & 0.2646 & 2.4484 \\
\hline 146 & 1.0435 & 0.4599 & 1.9998 & 0.5211 & 0.7023 & 0.2570 & 0.2916 & 2.4760 \\
\hline 181 & 0.9670 & 1.5412 & 1.6114 & 0.3854 & 0.3399 & 0.1888 & 0.2688 & 2.4913 \\
\hline 184 & 0.6768 & 0.8040 & 2.2075 & 0.3421 & 0.3449 & 0.1647 & 0.2390 & 2.4981 \\
\hline 197 & 0.9701 & 1.4591 & 2.6772 & 0.2406 & 0.3323 & 0.1864 & 0.2954 & 3.2312 \\
\hline 209 & 1.0726 & 1.5207 & 1.6171 & 0.1944 & 0.2493 & 0.1744 & 0.2485 & 2.4917 \\
\hline 210 & 0.6032 & 1.0894 & 2.0864 & 0.2784 & 0.3244 & 0.1584 & 0.2338 & 2.4722 \\
\hline 221 & 1.1669 & 1.5360 & 1.5047 & 0.2292 & 0.3028 & 0.2018 & 0.2602 & 2.4839 \\
\hline 232 & 1.0191 & 2.4900 & 1.8773 & 0.2109 & 0.2909 & 0.1521 & 0.3002 & 3.3038 \\
\hline 234 & 0.4674 & 3.9698 & 1.1972 & 0.2199 & 0.4099 & 0.2252 & 0.3197 & 4.2045 \\
\hline 235 & 0.4079 & 3.2560 & 2.0270 & 0.2652 & 0.2852 & 0.1864 & 0.3100 & 3.8811 \\
\hline 237 & 0.4370 & 1.8556 & 2.4619 & 0.3698 & 0.3698 & 0.2026 & 0.2878 & 3.1638 \\
\hline 244 & 0.7270 & 3.0402 & 1.1425 & 0.2973 & 0.2883 & 0.1477 & 0.2832 & 3.3571 \\
\hline 245 & 1.0758 & 3.1574 & 1.4160 & 0.4620 & 0.3320 & 0.2020 & 0.3434 & 3.6737 \\
\hline 247 & 0.7431 & 2.2760 & 1.3630 & 0.2482 & 0.4482 & 0.2482 & 0.2786 & 2.8132 \\
\hline 250 & 0.4091 & 2.0542 & 1.5004 & 0.0893 & 0.1993 & 0.1293 & 0.2094 & 2.5890 \\
\hline 255 & 0.5173 & 2.3343 & 1.5318 & 0.3575 & 0.3075 & 0.2004 & 0.2683 & 2.8854 \\
\hline 261 & 0.7331 & 1.9980 & 1.4120 & 0.2694 & 0.2594 & 0.1197 & 0.2429 & 2.5841 \\
\hline 269 & 0.3467 & 1.7218 & 2.1812 & 0.2096 & 0.3410 & 0.1410 & 0.2430 & 2.8324 \\
\hline 273 & 0.2090 & 2.4158 & 0.7254 & 0.0674 & 0.1074 & 0.0994 & 0.1688 & 2.5361 \\
\hline 288 & 0.9769 & 2.7587 & 1.0712 & 0.4699 & 0.2299 & 0.2470 & 0.3026 & 3.1697 \\
\hline 304 & 0.4765 & 2.4089 & 0.8561 & 0.1121 & 0.1921 & 0.1321 & 0.2038 & 2.6133 \\
\hline
\end{tabular}

PP: Prediction Point.

2.2. EM Field Measurements at Krajina Square. EM field broadband measurements were performed with portable system from Rohde\&Schwarz [7], which consists of FSH3 spectrum analyzer, TS-EMF three orthogonally isotropic antenna sensors with the tripod and laptop PC (Figure 5). In conjunction with software R\&S RFEX [8], which has been especially designed for environmental EM compatibility applications, the system has been used for accurate measurements and statistical evaluation of the resultant electric field strength in the frequency range from $30 \mathrm{MHz}$ to $3 \mathrm{GHz}$, particularly in densely populated areas. The isotropic radiation pattern of the sensor considerably simplifies measurements since it need not be carried out with different polarizations and in different directions. This means that the sensor used for measurements did not have to be positioned in any particular direction during the measurements, as the total electric field strength was calculated according to (4) for each band as follows:

$$
E_{\text {measured }}=\sqrt{E_{x}^{2}+E_{y}^{2}+E_{z}^{2}} \text {. }
$$

So, the results of measurement are mean values, in a long time interval ( $6 \mathrm{~min})$, of the electric field strength caused by six examined radio communication services. Measurement of total electric field strength in each point took 36 minutes of time, because 6 different bands were measured in each point.

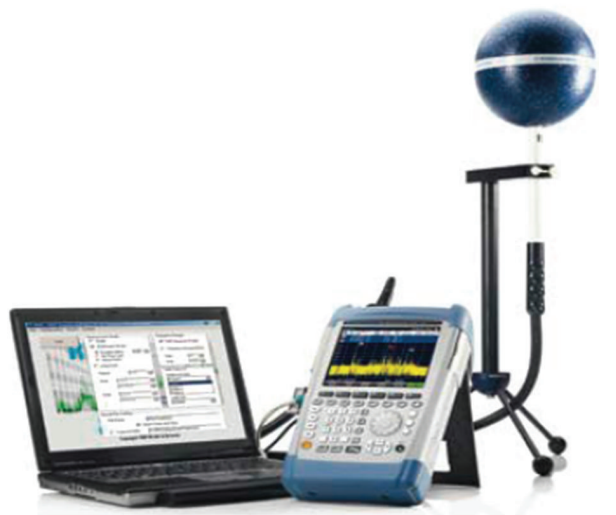

FIgURE 5: Portable system for EMF measurements.

Total electric field strength measurements were performed in accordance with [12], at the same 320 points in which the software prediction was previously performed.

Figure 6 shows measurement map of total electric field strength in the same 320 points, as it was previously indicated. Also, Table 3 presents the measurement results in the same 24 points in which the maximum values of $E_{T}$ were previously 
TABLE 3: Measurement results of total electric field strength at 24 maximum points.

\begin{tabular}{|c|c|c|c|c|c|c|c|c|}
\hline MP & $\begin{array}{c}E m_{1}(\mathrm{~V} / \mathrm{m}) \\
{[\mathrm{GSM} 900]}\end{array}$ & $\begin{array}{l}E m_{2}(\mathrm{~V} / \mathrm{m}) \\
{[\mathrm{DCS} 1800]}\end{array}$ & $\begin{array}{c}E m_{3}(\mathrm{~V} / \mathrm{m}) \\
{[\mathrm{UMTS}]}\end{array}$ & $\begin{array}{c}\mathrm{Em}_{4}(\mathrm{~V} / \mathrm{m}) \\
{[\mathrm{TV} 5-11]}\end{array}$ & $\begin{array}{l}E_{5}(\mathrm{~V} / \mathrm{m}) \\
{[\mathrm{TV} 21-66]}\end{array}$ & $\begin{array}{l}E m_{6}(\mathrm{~V} / \mathrm{m}) \\
{[\mathrm{FM} \text { radio] }}\end{array}$ & $\sum\left(E m_{T} / E_{L}\right)$ & $E m_{T}$ \\
\hline 23 & 0.2589 & 0.3886 & 0.6889 & 0.7718 & 0.4945 & 0.2822 & 0.1955 & 1.2698 \\
\hline 94 & 0.3937 & 0.5345 & 0.6337 & 0.2999 & 0.2365 & 0.2332 & 0.1395 & 1.0210 \\
\hline 118 & 0.1438 & 0.5919 & 0.5433 & 0.2598 & 0.2619 & 0.1574 & 0.1151 & 0.9094 \\
\hline 146 & 0.6533 & 0.4338 & 0.7891 & 0.3329 & 0.2805 & 0.1905 & 0.1598 & 1.2097 \\
\hline 181 & 0.3845 & 1.0720 & 0.6421 & 0.1868 & 0.1356 & 0.0754 & 0.1295 & 1.3297 \\
\hline 184 & 0.3669 & 0.6247 & 0.9586 & 0.1805 & 0.2176 & 0.1022 & 0.1311 & 1.2386 \\
\hline 197 & 0.3828 & 1.5517 & 1.3982 & 0.1272 & 0.1876 & 0.1274 & 0.1845 & 2.1394 \\
\hline 209 & 0.4479 & 1.4384 & 0.6244 & 0.1671 & 0.1996 & 0.0857 & 0.1527 & 1.6537 \\
\hline 210 & 0.3921 & 1.0047 & 0.8301 & 0.1491 & 0.1743 & 0.0784 & 0.1350 & 1.3824 \\
\hline 221 & 0.5371 & 0.7531 & 0.6184 & 0.1170 & 0.2185 & 0.0812 & 0.1253 & 1.1428 \\
\hline 232 & 0.4531 & 2.4590 & 0.6887 & 0.2031 & 0.1844 & 0.0833 & 0.2008 & 2.6093 \\
\hline 234 & 0.4663 & 3.8327 & 0.4863 & 0.1637 & 0.2263 & 0.1851 & 0.2608 & 3.9059 \\
\hline 235 & 0.3595 & 2.8084 & 0.7879 & 0.1856 & 0.2032 & 0.1231 & 0.2177 & 2.9543 \\
\hline 237 & 0.4928 & 1.6503 & 0.9499 & 0.2358 & 0.2628 & 0.1741 & 0.1970 & 2.0059 \\
\hline 244 & 0.5459 & 2.7362 & 0.4102 & 0.1602 & 0.2012 & 0.0664 & 0.2027 & 2.8326 \\
\hline 245 & 0.5830 & 2.6731 & 0.6678 & 0.2823 & 0.2429 & 0.0881 & 0.2291 & 2.8421 \\
\hline 247 & 0.3539 & 2.1035 & 0.5573 & 0.1354 & 0.2228 & 0.1427 & 0.1768 & 2.2246 \\
\hline 250 & 0.3346 & 1.9236 & 0.5154 & 0.0574 & 0.1271 & 0.0563 & 0.1436 & 2.0250 \\
\hline 255 & 0.4629 & 1.7947 & 0.7746 & 0.1758 & 0.1706 & 0.1132 & 0.1757 & 2.1268 \\
\hline 261 & 0.3320 & 1.8901 & 0.6324 & 0.2155 & 0.1670 & 0.0580 & 0.1644 & 2.0397 \\
\hline 269 & 0.2619 & 1.6806 & 0.9953 & 0.1921 & 0.2819 & 0.0698 & 0.1748 & 2.0012 \\
\hline 273 & 0.2381 & 2.3632 & 0.7945 & 0.0841 & 0.0582 & 0.1205 & 0.1704 & 2.5095 \\
\hline 288 & 0.6921 & 1.6638 & 0.8995 & 0.2970 & 0.1402 & 0.1502 & 0.2005 & 2.0462 \\
\hline 304 & 0.1912 & 1.9295 & 0.9795 & 0.0889 & 0.1225 & 0.0783 & 0.1588 & 2.1790 \\
\hline
\end{tabular}

MP: Measuring Point.

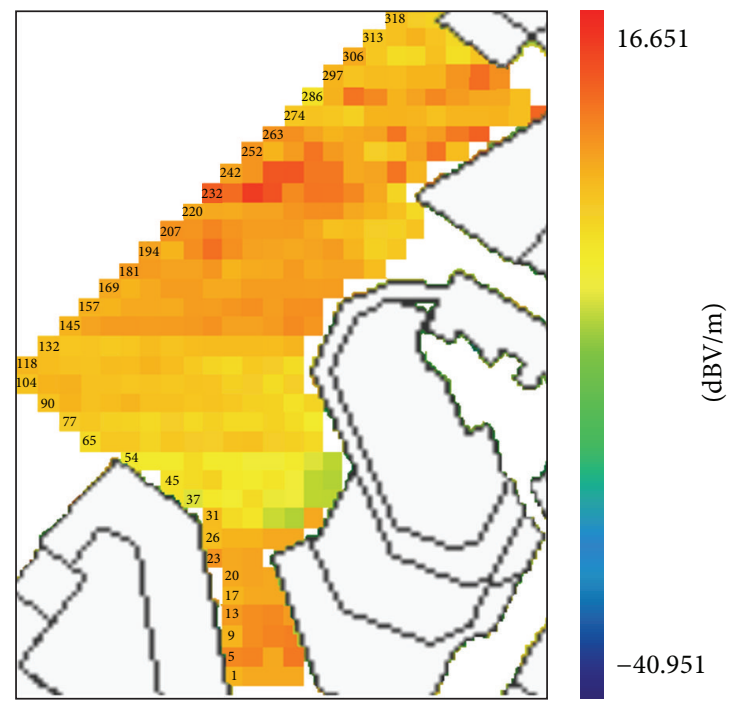

FIGURE 6: Total electric field strength measurements map.

the header of the table. In the eighth and ninth columns there are values of $\Sigma E m_{T} / E_{L}$ and the total electric field strength obtained by using (2) and (3) in which the measured electric field strength values are used, instead of the predicted ones.

2.3. Comparison of Measurement and Prediction Results. Comparison of measurement and software prediction results of total electric field strength was carried out in two ways, by visual comparison of colour maps and by the comparison of table results displayed in 320 points. Namely, it is obvious that colour maps are not the same but they have closely similar mosaics, because the points with maximum values are located at almost the same places. Table 4 shows, for example, a comparative overview of software prediction and measurement results of electric field strength in 24 points selected from the table with 320 measurement and prediction points. The fifth and the sixth columns are deviation $\sigma$, expressed in $\mathrm{V} / \mathrm{m}$, and deviation $\delta$, expressed in $\mathrm{dB}$, presented, respectively, and calculated in accordance with (5) as follows:

predicted, wherein $E m_{1}$ to $E m_{6}$ represent the measured electric field strength for six specified frequency bands in

$$
\begin{gathered}
\sigma=E_{T}-E m_{T} \\
\delta=10 \log \frac{E_{T}}{E m_{T}} .
\end{gathered}
$$


TABLE 4: Comparative overview of prediction and measurements results at 24 points with maximum values.

\begin{tabular}{lccccc}
\hline ON & $\begin{array}{c}\text { PP } \\
\text { MP }\end{array}$ & $E_{T}(\mathrm{~V} / \mathrm{m})$ & $\begin{array}{c}E m_{T} \\
(\mathrm{~V} / \mathrm{m})\end{array}$ & $\begin{array}{c}\text { Deviation } \\
(\mathrm{V} / \mathrm{m})\end{array}$ & $\begin{array}{c}\text { Deviation } \\
(\mathrm{dB})\end{array}$ \\
\hline 1 & 23 & 2.46 & 1.27 & 1.19 & 2.87 \\
2 & 94 & 2.35 & 1.02 & 1.33 & 3.62 \\
3 & 118 & 2.45 & 0.91 & 1.54 & 4.3 \\
4 & 146 & 2.48 & 1.21 & 1.27 & 3.11 \\
5 & 181 & 2.49 & 1.33 & 1.16 & 2.73 \\
6 & 184 & 2.5 & 1.24 & 1.26 & 3.05 \\
7 & 197 & 3.23 & 2.14 & 1.09 & 1.79 \\
8 & 209 & 2.49 & 1.65 & 0.84 & 1.78 \\
9 & 210 & 2.47 & 1.38 & 1.09 & 2.52 \\
10 & 221 & 2.48 & 1.14 & 1.34 & 3.37 \\
11 & 232 & 3.30 & 2.61 & 0.69 & 1.02 \\
12 & 234 & 4.20 & 3.91 & 0.30 & 0.32 \\
13 & 235 & 3.88 & 2.95 & 0.93 & 1.18 \\
14 & 237 & 3.16 & 2.01 & 1.16 & 1.98 \\
15 & 244 & 3.36 & 2.83 & 0.52 & 0.74 \\
16 & 245 & 3.67 & 2.84 & 0.83 & 1.11 \\
17 & 247 & 2.81 & 2.22 & 0.59 & 1.02 \\
18 & 250 & 2.59 & 2.02 & 0.56 & 1.07 \\
19 & 255 & 2.89 & 2.13 & 0.86 & 1.53 \\
20 & 261 & 2.58 & 2.04 & 0.54 & 1.03 \\
21 & 269 & 2.83 & 2.00 & 0.83 & 1.51 \\
22 & 273 & 2.54 & 2.51 & 0.03 & 0.05 \\
23 & 288 & 3.17 & 2.05 & 1.12 & 1.90 \\
24 & 304 & 2.61 & 2.18 & 0.43 & 0.79 \\
\hline $0 N$ & & & &
\end{tabular}

ON: Ordinal Number.

It is obvious from Table 4 that the predicted values of the total electric field strength are greater than the measured values at all observed points, and the diagram for 24 points with maximum values in Figure 7 shows that predicted values have their maximums at almost the same points as the measured values. In that way, the maximum value in the 234th point $(4.20 \mathrm{~V} / \mathrm{m})$, obtained by prediction, was confirmed by measuring the maximum value $(3.91 \mathrm{~V} / \mathrm{m})$ in the same point. The same case is at all the other points except at 118 th point $(0.91 \mathrm{~V} / \mathrm{m})$.

All of the stated above is confirmed by Figures 8 and 9 , as well, where it is clear that deviation $\sigma$ is in range from $0.054 \mathrm{~V} / \mathrm{m}$ up to $1.525 \mathrm{~V} / \mathrm{m}$ or deviation $\delta$ from $0.046 \mathrm{~dB}$ up to $4.44 \mathrm{~dB}$.

2.4. Discussion. Results obtained by software prediction and measurements are different because the mobile traffic changes significantly over time. Namely, some objects are changing their position versus time which leads to hardly predictable field distributions. Such moving scatterers can be not only persons or cars but also windows or doors. Apart from the impact of such objects, the influence of seasonal variations and the weather should also be considered. Field propagation can vary due to snow, rain, and other ambient

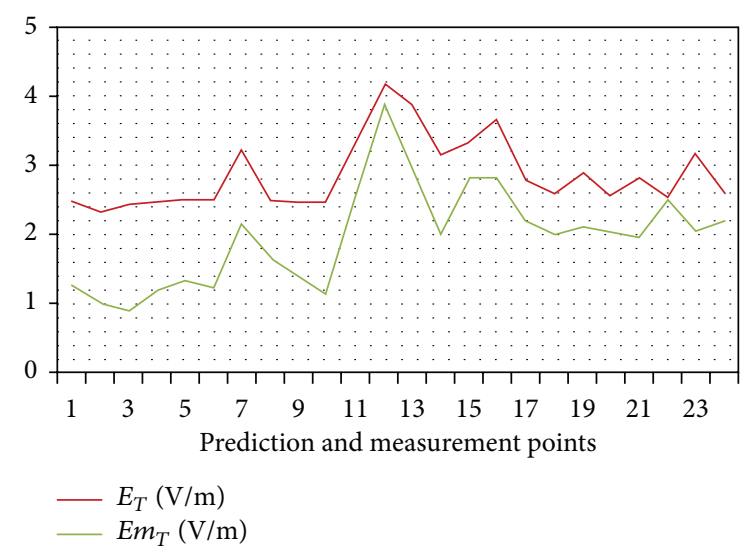

FIgURE 7: The diagram of 24 points with maximum values.

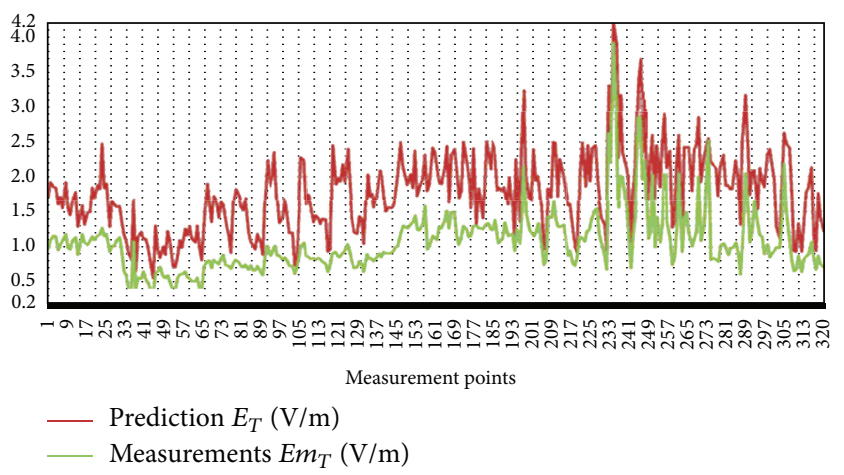

FIGURE 8: Predicted and measured values of total electric field strength.

conditions, for example, wet versus dry ground, snow, and humidity.

Also, as a rule, the predicted values exceed the measured ones. That is the consequence of the software approximation of some parameters and because of the influence of the environment leading to multipath EM wave propagation causing fading effects due to multiple reflections, disseminations, diffractions, and absorptions of the signals on different objects, for example, buildings, ground, or trees which do not exist in the digital city map in this case. The measurement results are 6-minute mean values in contrast to the prediction results where it is presumed that transmitters work continuously and simultaneously. In addition, it should be noted that within contemporary mobile base stations two significant techniques are applied: automatic power control (the power transmitted by the base stations can be changed depending on the propagation conditions that exist between base station and mobile terminal) and the radiation with interruptions (transmitter of base station can be excluded from transmitting the signals when the speaker stops his conversation). However, spatial field distributions derived by prediction and measurement have close similarity, and predicted values have their maximums at almost the same points as the measured values. Therefore, WI software is a reliable tool for planning of territory signal coverage and 


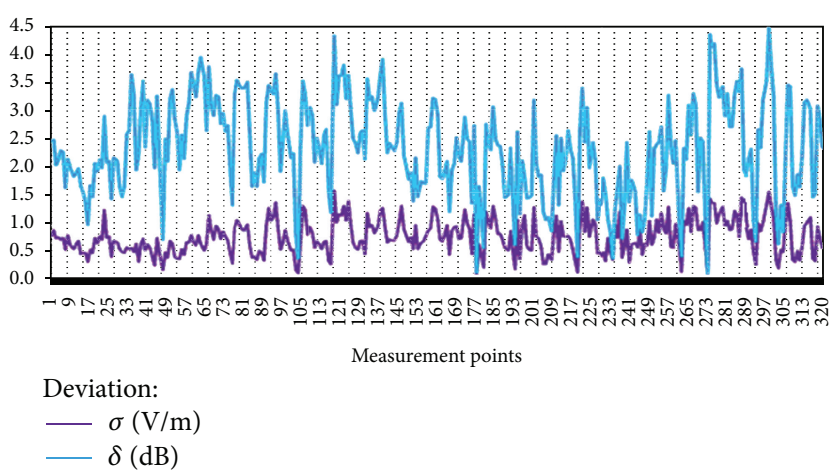

FIGURE 9: Deviation and logarithmic quotient of predicted and measured values of total electric field strength.

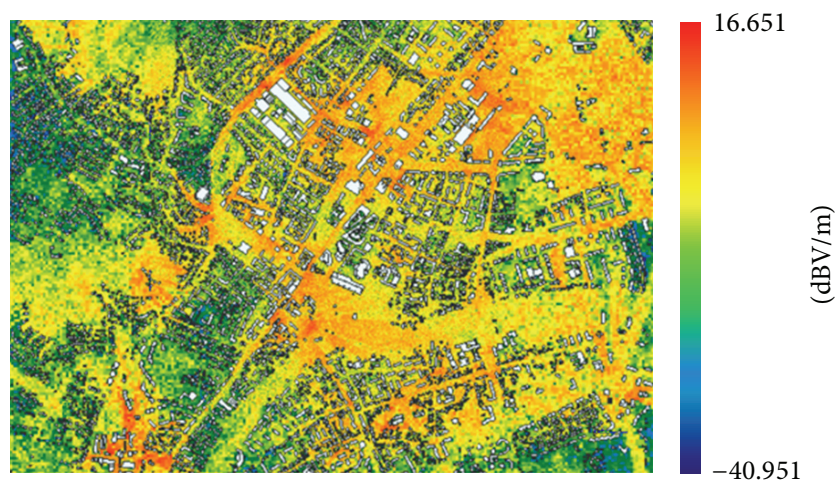

FIgURE 10: Total electric field strength prediction map of DCS1800 MHz mobile service.

especially for locating the points at which the maximum value of the electric field strength can be expected.

\subsection{Locating of the Points with the Maximum Value at Area} Surface of about Ten Square Kilometres. At first, a software prediction for total electric field strength for each of the licensed sources of EM radiation, such as GSM $900 \mathrm{MHz}$, DCS1800 MHz, UMTS2100 MHz, TV 5-12th channel, TV 2166 th channel, and FM radio, was conducted separately in the wider city centre of Banja Luka (area of about $10 \mathrm{~km}^{2}$ surface), in the same way as it had previously been performed for significantly smaller surface. Here typical representatives are, for example, only total electric field strength prediction maps of DCS1800 MHz mobile (Figure 10) and TV 5-12th channel broadcasting services (Figure 11).

These figures clearly show that the levels of electric field strength values had been incurred due to broadcasting of TV and FM radio transmitters and that they are significantly lower than the levels caused by radiation of mobile systems on this area. This means that those lower levels have negligible impact on maximum values of electric field strength, and therefore they are not taken into account in further consideration. Using suitable selection of minimum and maximum value of electric field strength in colour legend given by WI software [6], maps with very visible maximum values (red points) were obtained. A map of maximum values

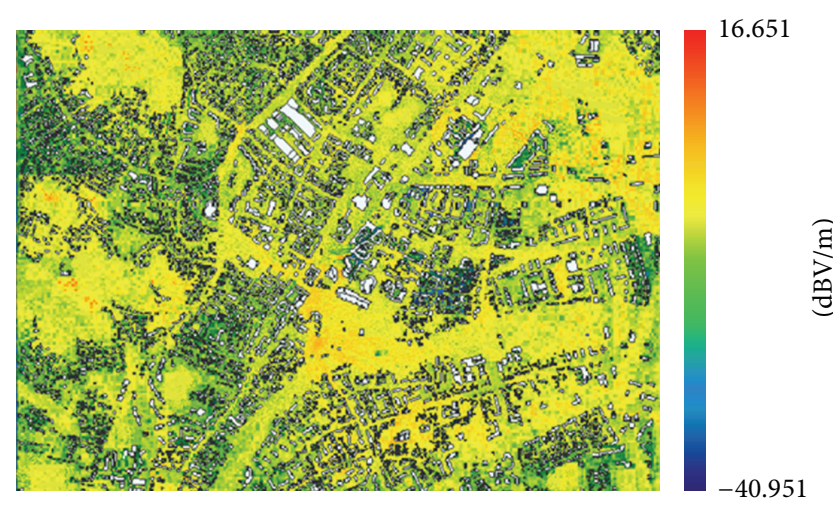

FIGURE 11: Total electric field strength prediction map of TV 5-12th channel broadcasting service.

of total electric field strength (Figure 13(b)) was obtained quickly and simply by overlapping maps of maximum values of total electric field strength caused by radiation of mobile systems (Figures 12(a), 12(b), and 13(a)). Of course, in the map legend of total electric field strength, different minimum and maximum values $(7$ and 10$) \mathrm{dBV} / \mathrm{m}$ are selected, in relation to mobile services ( 4 and 6 ) $\mathrm{dBV} / \mathrm{m}$. Now it was very easy to determine the location of points with maximum values by additional measurements approximately in twenty points in areas labelled with red colour, in order to precisely locate points with maximum values of total electric field strength [6].

Those points are shown in Table 5 in rows from the highest $\left(M_{1}\right)$ to the lowest $\left(M_{10}\right)$ maximum values (except the predicted values in points $M_{2}$ and $M_{7}$ ). Figure 14 shows diagrams of ten predicted and measured maximum values of total electric field strength and the sum of quotient obtained by using (3). Although measured values are mainly less than predicted values, however, they follow the predicted values (except in point $M_{7}$ ), so the measured maximum values are located in most of the cases at the same places as the predicted ones. For easier orientation, all points with maximum values of total electric field strength are labelled on Google map in Figure 15.

\section{Conclusion}

A satisfying similarity between prediction and measurement results is actually a verification of Wireless InSite (WI) software accuracy and it can be stated that WI is acceptably accurate and is a very reliable urban wave propagation calculation tool for planning and designing mobile wireless networks.

As such, it can be successfully used to locate the points in which the maximum values of the total electric field strength can be expected, like places for the potential installation of sensitive measuring sensors, as the basic components of the system for continuous remote monitoring and storage of nonionizing EM field radiation values.

Also, the measurement results indicate that the nonionizing electromagnetic radiation levels are several times below 


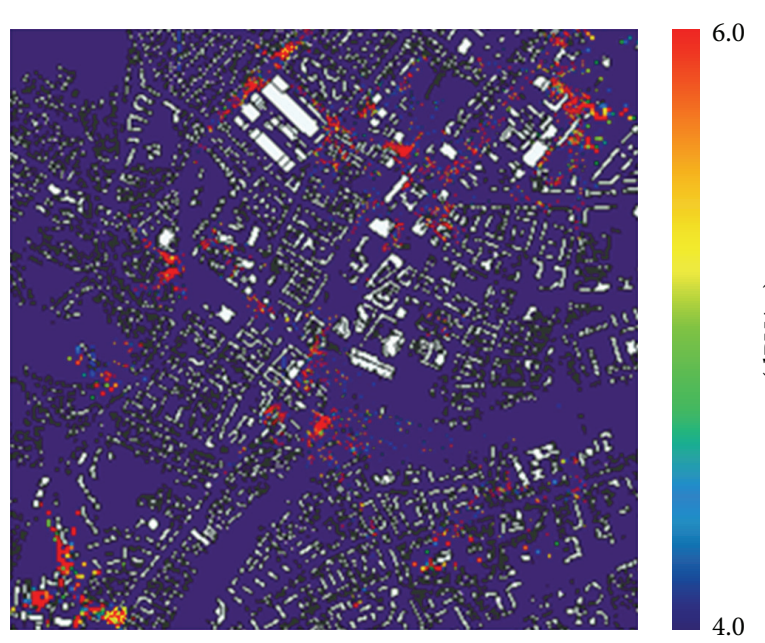

(a) GSM900 MHz

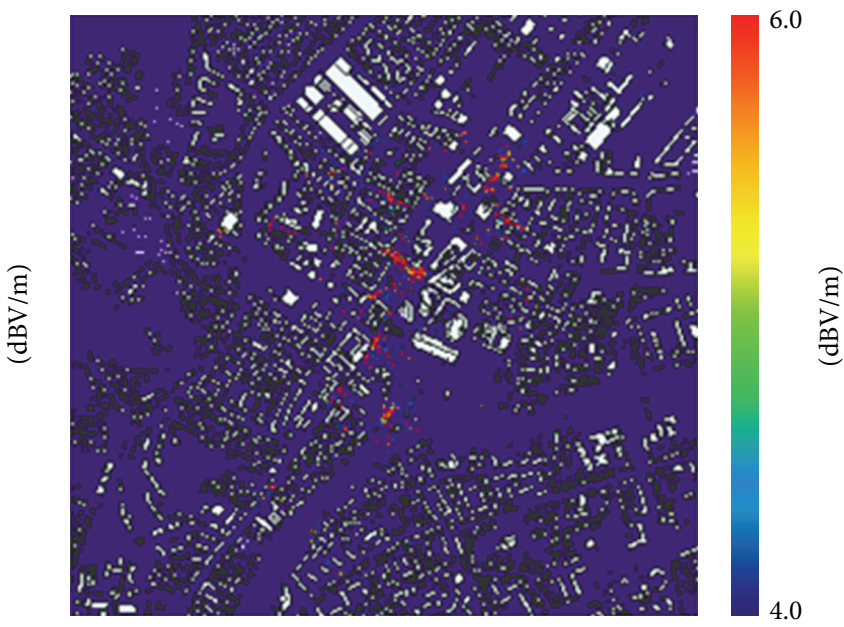

(b) DCS1800 MHz

FIGURE 12: Maps of maximum values of total electric field strength for GSM900 and DCS1800 mobile services.

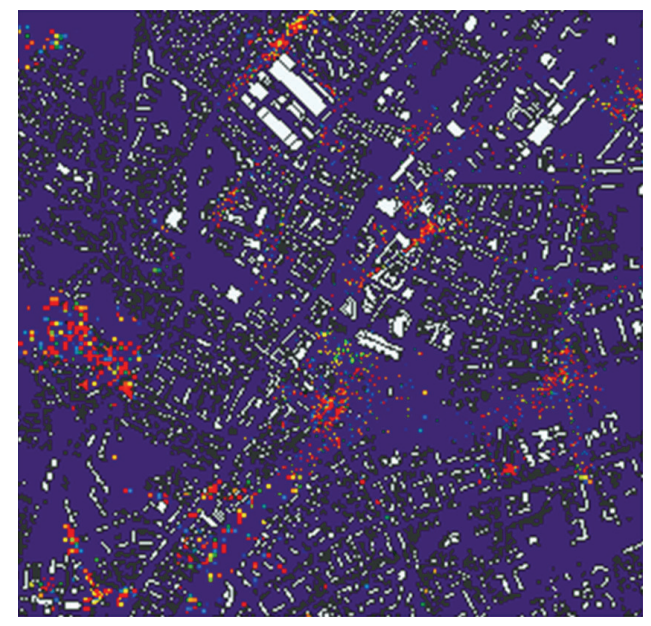

(a) UMTS2100 MHz
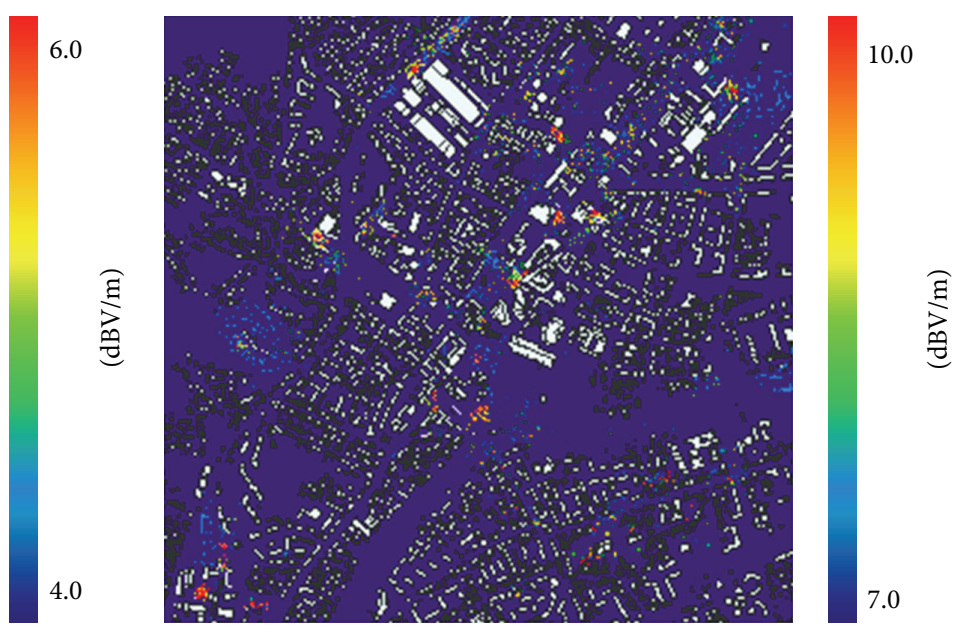

(b) Total electric field strength

FIGURE 13: Maps of maximum values of total electric field strength for UMTS2100 and total electric field strength.

TABLE 5: Locations of points with maximum values of total composite electric field strength.

\begin{tabular}{|c|c|c|c|c|c|}
\hline Maximum & Location & $E_{T}(\mathrm{~V} / \mathrm{m})$ & $\sum E_{T} / E_{L}$ & $E m_{T}(\mathrm{~V} / \mathrm{m})$ & $\sum E m_{T} / E_{L}$ \\
\hline M1 & R.K. Boska & 4.21 & 0.32 & 3.91 & 0.26 \\
\hline M2 & Castle & 5.27 & 0.45 & 3.69 & 0.28 \\
\hline M3 & V.Z. Cosmos & 4.84 & 0.37 & 2.55 & 0.21 \\
\hline M4 & Houses of Parliament & 4.63 & 0.37 & 2.15 & 0.17 \\
\hline M5 & Houses of Government & 3.92 & 0.36 & 2.14 & 0.23 \\
\hline M6 & Banski dvor & 3.91 & 0.27 & 2.10 & 0.28 \\
\hline M7 & High building & 1.29 & 0.10 & 2.07 & 0.14 \\
\hline M8 & Cajavec & 3.89 & 0.31 & 1.96 & 0.21 \\
\hline M9 & Ring stream-Laus & 3.88 & 0.28 & 1.86 & 0.16 \\
\hline M10 & Hotel Bosna & 3.87 & 0.38 & 1.46 & 0.15 \\
\hline
\end{tabular}




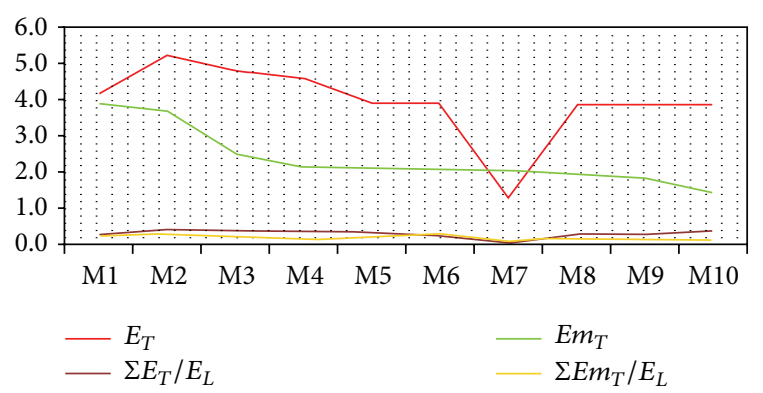

FIGURE 14: Diagrams of total electric field strength and the sum of quotient.

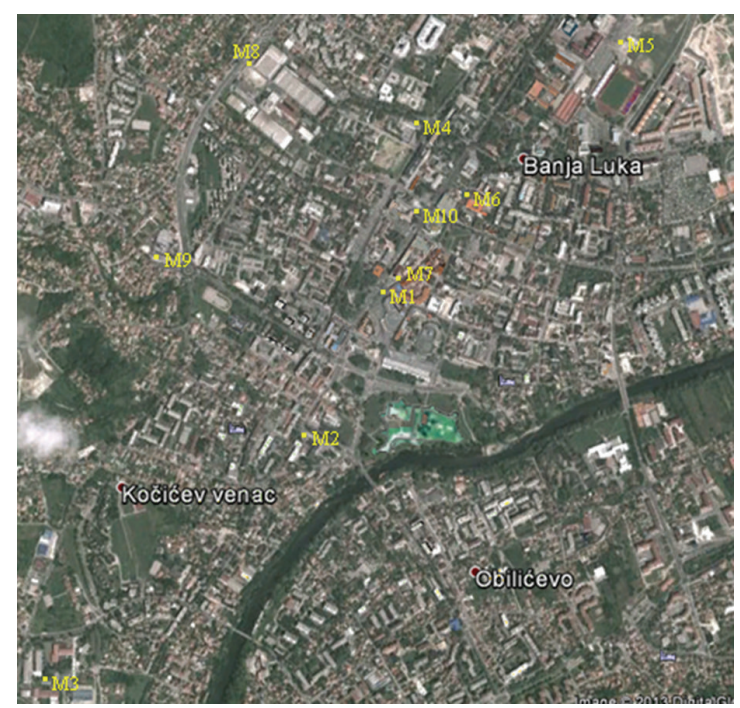

FIGURE 15: Points of total electric field strength maximums in the wider city centre of Banja Luka.

the reference levels defined by the European Commission Recommendation 1999/519/EC and the Bosnia and Herzegovina Rulebook 37/2008, and there is no danger to general population health in this case.

Generally speaking, the results presented in this paper indicate that this modern experimental method is very useful and practical, especially when a new telecommunication infrastructure is planned or inserted in a context where other installations already exist, for fast and efficient detection of possible locations with critical values of total electromagnetic fields that could endanger human health.

In other words, during a base station planning phase, it is necessary to take into account the fact that the field level in proximity of the structure should not exceed the safety values, no matter if the station is a single structure or coexisting with other similar installations. In such case, a reduction of emitted power of the station itself or of the surrounding emitting structures should be imposed.

Actually, the method described here provides the possibility to each subsequent new-projected source of EM radiation to be positioned that way, so such situation cannot occur.

\section{Conflict of Interests}

The authors declare that there is no conflict of interests regarding the publication of this paper.

\section{Acknowledgments}

The authors express their thanks to the financial support from the Ministry of Science and Technology of the Republic of Srpska, Bosnia and Herzegovina. The authors owe special thanks to the engineers from the Faculty of Electrical Engineering, University of Banja Luka, and the Institute for Protection, Ecology and Informatics for the unstinting support and assistance during the conduction of a large number of measurements.

\section{References}

[1] International Commission on Non-Ionizing Radiation Protection (ICNIRP), Guidelines for Limiting Exposure to TimeVarying Electric, Magnetic, and Electromagnetic Fields (up to 300 $\mathrm{GHz}), 2009$.

[2] The Council of Communications Regulatory Agency, "Rulebook 37/2008 on limiting the emission of electromagnetic radiation," Official Gazette B\&H, no. 80/08, October 2008.

[3] F. Troisi, M. Boumis, and P. Grazioso, "The Italian national electromagnetic field monitoring network," Annals of Telecommunications, vol. 63, pp. 97-108, 2008.

[4] A. Gotsis, N. Papanikolaou, D. Komnakos, A. Yalofas, and P. Constantinou, "Non-ionizing electromagnetic radiation monitoring in Greece," Annals of Telecommunications, vol. 63, pp. 97-108, 2008.

[5] P. Međjedović and D. Šuka, "Softwares for urban electromagnetic wave propagation modelling," Infoteh-Jahorina, vol. 11, pp. 422-427, 2012.

[6] Remcom Development Sector, Radio Propagation Prediction Software, User's Manual Version 2.3, Remcom Company, State College, Pa, USA, 2005.

[7] Rohde\&Schwarz, Test and Measurement Division, "User Manual Spectrum Analyzer FSH3 Id. Nr.1145.5973.11," http://www. rohde-schwarz.com/en/home_48230.html.

[8] Rohde\&Schwarz, Sotware Division, "Software Manual RFEX, Id. Nr. 1140.7984.03," München, Germany, http://www.rohdeschwarz.com/en/home_48230.html.

[9] http://croatia.gdi.net/.

[10] P. Međjedović, M. Veletić, and Đ. Kolonić, "Software prediction of electromagnetic field strength in urban area of Banja Luka," in Proceedings of the 12th International Electrotechnical and Computer Science Conference (ERK '11), pp. 168-171, Portorož, Slovenia.

[11] P. Međjedović, M. Veletić, and Ž. Blagojević, "Wireless insite software verification via analysis and comparison of simulation and measurement results," in Proceedings of the 35th International Convention (MIPRO '12), pp. 912-917, 2012.

[12] Electronic Communications Committee (ECC), "Revised ECC recommendation (02)04-measuring non-ionising electromagnetic radiation (9 kHz-300 GHz)," CEI IEC 61566, Brussels, Belgium, 2004. 

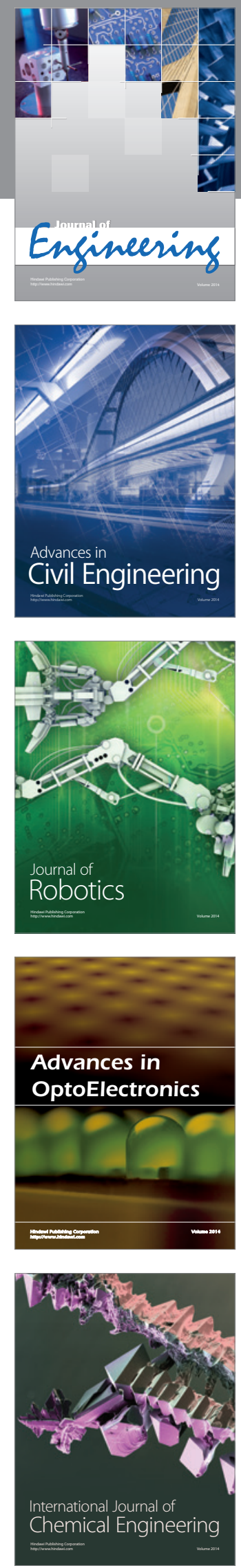

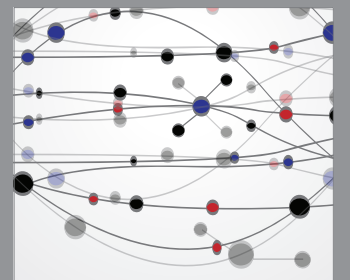

The Scientific World Journal
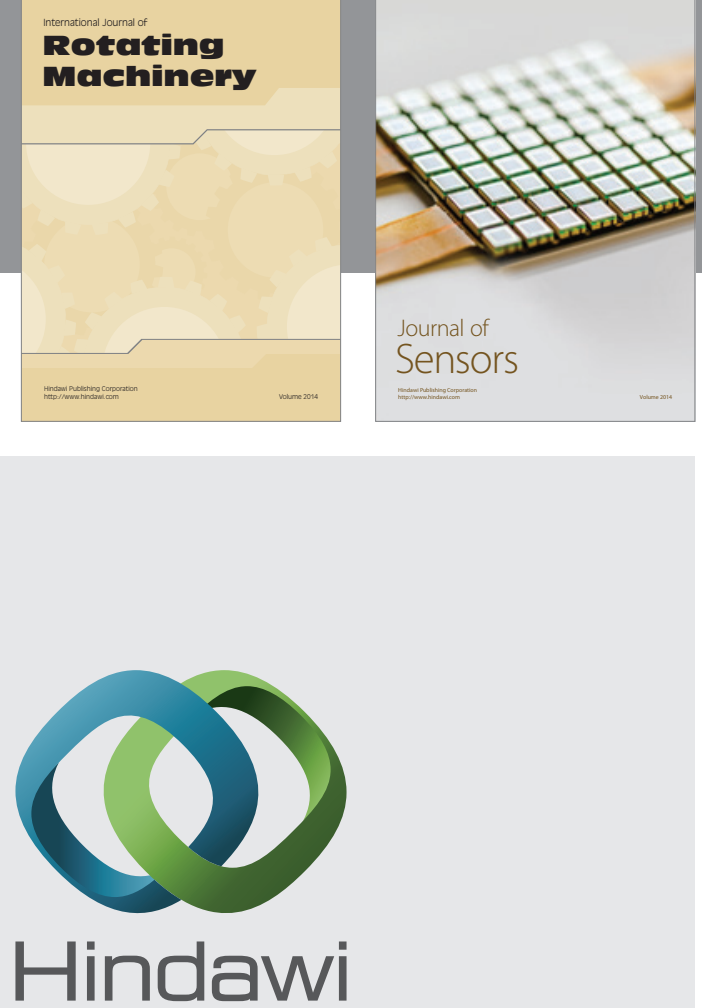

Submit your manuscripts at http://www.hindawi.com
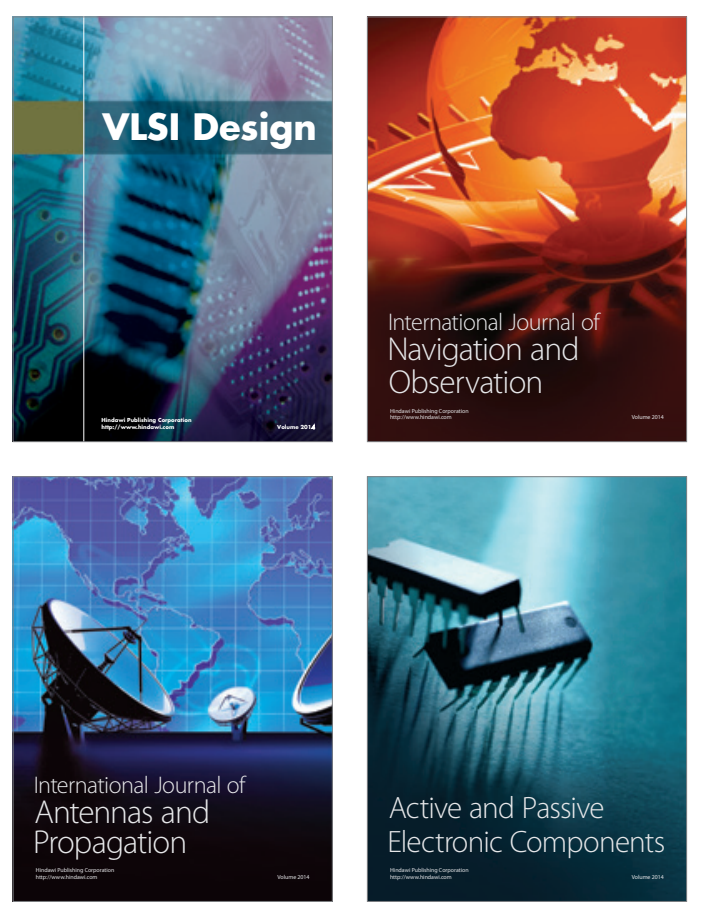
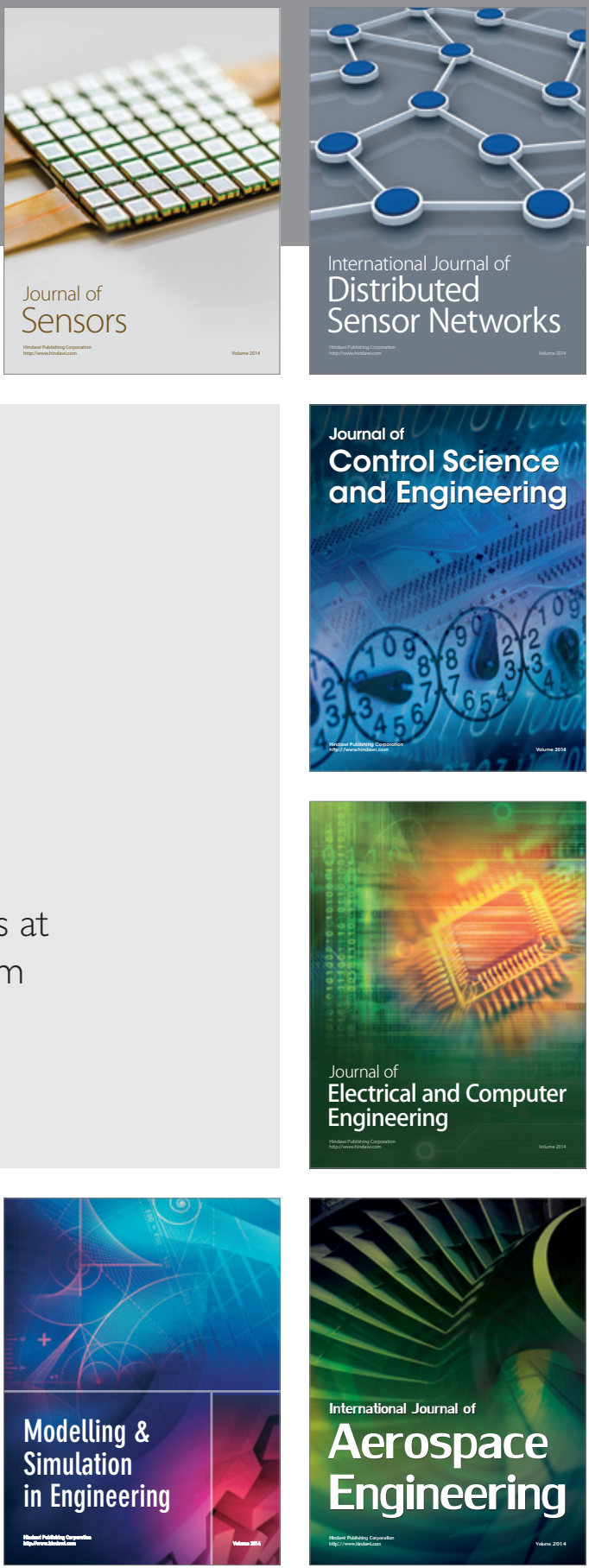

Journal of

Control Science

and Engineering
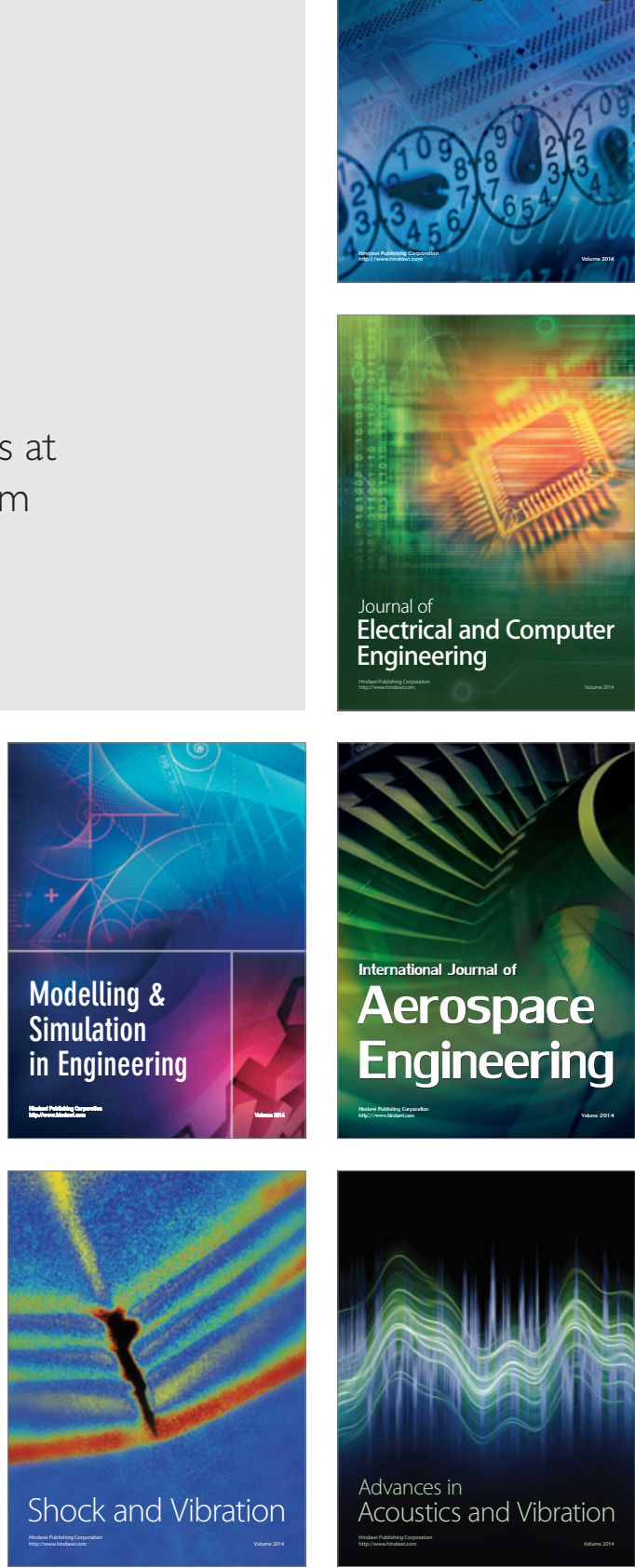